\title{
POÉTICAS DO CINEMA DE ANIMAÇÃO: INVENÇÃO E RUPTURA (1920 - 2015)
}

\author{
Fernando Teixeira Luiz \\ Universidade do Oeste Paulista - UNOESTE, Letras, Pedagogia e Artes Visuais, E_mail: fer.luiggi@hotmail.com
}

\begin{abstract}
RESUMO
Índices expressivos de bilheteria atestam que o gênero animação é aclamado por crianças e adolescentes, embora não integre, de maneira efetiva, o cotidiano escolar, que prioriza a leitura do cânone literário a partir de uma proposta metodológica ainda didatizadora, monológica e estruturalista. Os desenhos animados, desse modo, penetrariam nas unidades de ensino como gênero marginal, vivo e incisivo nas falas e comportamentos dos alunos. Tendo em vista esse quadro, a presente pesquisa tem como principal objetivo problematizar as propostas estéticas veiculadas em desenhos tradicionais e contemporâneos, produzidos, divulgados e comercializados em diferentes países. Para tanto, a investigação, fundamentada no dialogismo bakhtiniano, analisou duzentas e quinze produções lançadas ao longo de quase cem anos, comercializadas em DVDs ou disponibilizadas na internet, especificamente no You Tube. Almeja-se, desse modo, a partir dos recursos empregados pelos estúdios na tecitura do texto visual e das múltiplas vozes instauradas ao longo dos desenhos, identificar as propostas artísticas tanto em narrativas mais "formais", veiculadas nos anos de 1960 e 1970, quanto nas produções mais "arrojadas", firmadas após a década de 1990, de natureza polissêmica e emancipatória, marcadas pela metalinguagem, pela polifonia, pela incidência de heróis excêntricos, por anacronismos, pelas inúmeras alusões à cultura pop e, em especial, pela intertextualidade.
\end{abstract}

Palavras-chave: Desenho animado; estética; dialogismo; infância; ideologia.

\section{POETICS OF ANIMATED FILM: INVENTION AND DISRUPTION (1920 - 2015)}

\begin{abstract}
Significant box office indices show that the animation genre is acclaimed by children and adolescents, although it does not make part of the school routine effectively, which prioritizes reading the literary canon from a methodological proposal that is still focused in teaching, monological and structuralist. Cartoons thereby penetrate the teaching units as marginal genre, alive and incisive in the statements and behavior of students. Given this context, this research aims to question the aesthetic proposals conveyed in traditional and contemporary cartoons, produced, disseminated and marketed in different countries. Therefore, the research, based on Bakhtin's dialogism, analyzed two hundred fifteen productions lauched during nearly a hundred years, sold on DVDs or made available on the internet, especially on YouTube. So, the aim is to, from the resources employed by the studio in the production of the visual text and multiple voices brought over the drawings, identify the modes of representation addressed to its ethnic group and to other people as well as the space directed to children as much as in the more "formal" narratives aired in the 1960s and 1970s, as in the more "bold" productions, estabilished after the 1990s, of a polysemic and emancipatory nature, marked by the meta-language, the polyphony, the incidence of eccentric heroes, by anachronisms, the numerous allusions to pop culture and, especially by the intertextuality.
\end{abstract}

Keywords: Cartoon; aesthetics; dialogism; childhood; ideology. 


\section{INTRODUÇÃO}

A pesquisa Poéticas do Cinema de Animação tem como principal meta identificar, mapear e problematizar as propostas estéticas que orientaram os desenhos animados ao longo do século XX. A rigor, justifica-se em meio à necessidade de uma reflexão um pouco mais aprofundada acerca dos desenhos veiculados no cenário contemporâneo em DVDs, TV e internet. Nota-se que tal gênero quase sempre é abordado como apêndice da história do cinema - o que elucida a incipiente bibliografia endereçada a tal questão. Na verdade, as animações destinadas ao público infanto-juvenil inscrevem-se como produtos de inegável impacto no mercado cinematográfico. Seduzem, encantam e emocionam mediante roteiros que, marcados pelo hibridismo, transitam da comédia ao drama, do suspense à aventura, do romance ao musical. Tendo em vista esse quadro, o estudo que envolve a mencionada temática ocupa-se em discutir o caráter artístico e ideológico de um conjunto de animações que circulam (e circularam) dentro e fora de unidades públicas e privadas de ensino, abordando as propostas estéticas diluídas na composição de roteiros, cenários, heróis e, sobretudo, personagens crianças.

A fim de melhor problematizar a singularidade do desenho animado como produto plurissignificativo, altamente artístico, como também sua considerável relevância para a criança, optou-se por estabelecer uma periodização acerca da presente temática. Para tanto, dividiu-se as duzentas e quinze produções consultadas em quatro momentos distintos identificados como: período de formação, consolidação e legitimação do gênero (1920 - 1960), período de desenvolvimento e expansão do mercado (1960 - 1980), período das narrativas híbridas, de tom grandiloquente e épico (1980 - 2000) e, finalmente, o período pós-moderno (2000 a 2015), marcado pela multiplicidade de vozes de grupos até então marginais, secundários e excêntricos.

\section{METODOLOGIA}

A presente pesquisa, de caráter documental, fundamenta-se nas vertentes teóricas que abordam a escritura artística não apenas em sua imanência, mas também em sua dimensão pragmática, examinando-a, prioritariamente, em sua historicidade, em sua horizontalidade e em sua verticalidade. Nessa linha, recorremos aos estudos de Stam (2003), Glaber (2009), Fossatti (2009) e Denis (2010). Ademais, a pesquisa também se pautou nas contribuições de Ariès (1978) no que diz respeito, especificamente, ao conceito de infância aqui tratado, e às pesquisas de Aumont e Marie (2003) e Xavier (2008), em torno da linguagem do cinema.

Paralelamente, estruturou-se mediante a leitura e compilação de duzentas e quinze animações, divididas, com base na cronologia, em quatro grupos. A opção por um quadro tão denso possibilitou mapear, de maneira efetiva, os modos de representação de crianças, famílias e outros grupos sociais, bem como as aspirações evidenciadas no mercado, a seleção de signos com base em determinado projeto ideológico e, sobretudo, a projeção de obras com propostas alternativas ao que era desenvolvido nos eixos Estados Unidos/ Canadá/ Inglaterra.

\section{RESULTADOS}

Bastante expressiva foi a produção cinematográfica, inscrita no gênero animação, projetada nas salas de exibição entre 1920 e 1960. Nesse circuito, desenvolveram-se os episódios pioneiros de Popeye, Betty Boop e Gato Félix, seguidos pela revolução conceptual instaurada por Walt Disney. Revolução essa impressa nas atuações de Mickey e na veiculação de uma série de desenhos em torno de títulos consagrados pela crítica - o cânone - e textos praticamente desconhecidos do grande público. Com o apogeu da Disney, outros estúdios, ainda que em menor grau, passaram a divulgar narrativas em que a subversão do anti-herói acabava se impondo na tecitura do discurso, como sugeriam os desenhos rubricados por Walter Lantz e, mais tarde, pela Warner. 
Ao todo, verificou-se que as trinta e cinco animações citadas no presente período (1920 1960) englobavam núcleos não muito heterogêneos de personagens. Compilando esse material, especialmente no que diz respeito aos protagonistas, constatou-se que a maior parte era masculina. Ressaltavam-se, especificamente, vinte e seis homens, contrastando-se com sete mulheres, identificadas como Betty Boop, Alice, Luluzinha e as princesas Cinderela, Aurora e Branca de Neve. Como se vê, a Disney sinalizava uma estética, ainda que requintada, bastante tradicional, preconizando a fragilidade feminina e a força intempestiva do homem branco, cristão e intrépido, latente nos arquétipos dos príncipes, maridos, cavaleiros e pais. A incidência de heróis modelares se fazia igualmente expressiva. Ao todo, eram vinte e nove protagonistas solidários a essa linhagem - a maior parte divulgada pela Disney - perante apenas quatro anti-heróis, cuja aparição devia-se, possivelmente, ao anseio de delinear propostas alternativas ao cinema de animação da época. Por outro lado, resta atentar quanto à explícita presença de adultos ( vinte e cinco no total), revelando um evidente descompasso face a oito crianças detectadas como protagonistas de animação. Dessas oito, Peter Pan integrava uma narrativa em que as relações familiares se aproximavam do modelo libertário proposto por Zilberman (1982). Já Luluzinha, apesar de assimilar, na década de 1940, um modelo alinhado ao viés eufórico, constituía um caso à parte. A personagem citada, devido à insubmissão e à acidez contestadora, parecia resistir à retórica moralizante que regia o curta-metragem.

Com o tempo, estampou-se, entre 1960 e 1980, um novo quadro que, em parte, destoaria do que se visualizou até então. A Walt Disney e a Warner mantiveram a liderança, ao passo que a TV se firmava como principal meio de entretenimento, e não mais as salas de cinema. Visualizouse, a partir de agora, o boom de curtas atrelados aos nomes de Willian Hanna e Joseph Barbera, conhecidos, até aquele contexto, pelas aventuras de Tom e Jerry. Configurou-se, de 1960 a 1980 , um corpus bastante eclético para consulta e posterior problematização. 0 corpus em questão abrangia um quadro de cinquenta e cinco animações que giravam em torno do substrato fabular, dos núcleos familiares, da ficção de suspense e da trajetória de heróis afinados aos arquétipos dos mitos gregos. A expansão do mercado evidenciou nichos em outros pólos fora do eixo norteamericano, possibilitando a criação de estúdios em novas realidades, como a Itália, a França, o Japão e o Brasil.

Ademais, o desenho animado, em sua historicidade, englobava tardiamente um olhar libertador sobre mulheres, negros, homossexuais e, sobretudo, crianças. A maior parte das produções, desenvolvidas entre 1930 e 1980, preconizava uma relação assimétrica do adulto perante meninos, pré-adolescentes e adolescentes, exaltando-lhes a fragilidade e a necessidade da obediência e da submissão. Entretanto, sabe-se que, nas últimas décadas do século XX, ganhava força a tendência de representar heróis primordiais na condição de jovens altaneiros. A mediação do adulto como indivíduo experiente e soberano - vale lembrar o enigmático Mestre dos Magos, de Caverna do Dragão (1983), e o paternal Jagua, de Thundercats (1985) - passou a ser esporádica. No geral, as personagens deviam lidar com seus dilemas e superá-los sem a intervenção de anciões, os quais, ainda que oniscientes, em nenhum momento demonstravam obsessão superprotetora.

Dos sessenta títulos compilados nessa nova fase (1980 - 2000), verifica-se que as mulheres, ainda que não ocupassem o posto de protagonistas - exceto She-ra, a princesa de Ethéria desfilavam como amazonas, secretárias ou feiticeiras. Diferenciavam-se das clássicas princesas da Disney, inspiradas na literatura tradicional dos irmãos Grimm, que rogavam pela presença masculina para reverenciá-las e livrá-las de determinada ameaça. As novas mulheres, desse modo, não mais se sujeitavam à imposição do pai, do amante ou do amigo. Porém, torna-se ainda difícil afirmar, de modo categórico, que aqui se configure abertamente a emancipação feminina, mas talvez o primeiro passo para o posterior surgimento de personagens na linha de Fiona (Shrek (2000)). As próprias heroínas da Disney, a partir desse novo contexto, não serão mais 
representadas com base em valores como recato, pureza e subordinação. Exemplo disso é Ariel, a protagonista de A pequena sereia (1989), capaz de desafiar a tradição imposta pelo próprio pai, o rei Tritão, e lutar contra as forças do destino para se tornar humana e conquistar o enérgico Érik.

No final da década de 1990, a tendência pós-moderna configurou-se mediante traços bastante singulares, como a ênfase à metalinguagem, a recorrência deliberada da intertextualidade, a mistura consciente de estilos e a incidência da alegoria. Assinala-se, em meio à filmografia veiculada no novo milênio, a presença exaustiva da categoria longa-metragem. Durante muito tempo, apenas a Disney investia em narrativas mais extensas, liderando o mercado cinematográfico com a releitura dos contos de fadas. Com o êxito de Shrek, parte expressiva dos estúdios norte-americanos percebeu a possibilidade de se inserir no citado mercado, desafiando o império do camundongo Mickey. O resultado (identificado entre 2000 - 2015) foi o novo boom do cinema de animação, contabilizando elevadas cifras, roteiros demorados e criações erigidas ante a técnica da computação gráfica. Desfilavam, assim, figuras que, gradativamente, tornaram-se familiares aos pequenos leitores, como o leão Alex, o camaleão Rango, o urso Pô e a princesa Frozen. Em maior ou menor grau, eram obras marcadas por tópicos que os estudos bakhtinianos classificariam como polifonia, carnavalização e dialogismo, abrangendo, também, múltiplas referências à cultura pop e, simultaneamente, à arte erudita.

Desse modo, observou-se nas sessenta e cinco narrativas consultadas que as verdades eurocêntricas e as certezas extremistas heterocêntricas acabavam sendo questionadas, desestabilizadas e problematizadas, edificando um discurso de tolerância e inclusão sem aderir a nenhum ranço utilitarista ou pedagógico. Firmando-se como uma expressão audiovisual, abusa de situações cômicas (gags), cria momentos em que contracenam atores e toons (cross over) e abre margem para pequenos videoclipes, ressaltando, assim, momentos mágicos em que partes do enredo são assinalados, tendo como fundo determinada melodia de forte apelo popular e comercial. Vigora, paralelamente, um conjunto de vozes variadas, oriundas das mais diversas camadas sociais, alinhadas ao multiculturalismo e marcadas pelo uso diversificado da linguagem. Encontravam-se tais vozes diluídas na participação de uma miríade de personagens (o plebeu (A nova onda do imperador (2000)), os habitantes do submundo (Por água abaixo (2006)), os peixes adeptos à cultura negra norte-americana (O Espanta-Tubarões (2004)), o camaleão pícaro (Rango (2011)), os guetos cariocas (Rio (2011)) e o universo do Brasil interiorano (O Sítio do Picapau Amarelo (2012)). Por outro lado, merecem também destaque os modos como o passado histórico - sobretudo a Idade Média e o Velho Oeste - são tratados face à ironia e ao humor desregrado. Assim, a historiografia oficial acabava sendo revisitada com sarcasmo, dessacralizando o mito do mártir emblemático, do herói clássico ou do cavaleiro astucioso. Evoca-se também o hibridismo explícito na maior parte das obras consultadas, que não se enquadravam em um único gênero, mas se abriam para ecléticas classificações, abarcando, simultaneamente, a comédia, o drama, a aventura e o suspense.

\section{DISCUSSÃO}

Ismail Xavier ${ }^{1}$ pontua que o cinema, embora tenha dado seus primeiros passos no século XIX, consolidou-se, definitivamente, somente no século XX. Promovendo o que o autor denomina como espetacularização da vida - transformando o cotidiano em imagem - tornou-se, em pouco tempo, expressivo veículo de comunicação de massa. Até a década de 1950, inclusive, caracterizava-se como principal meio de entretenimento, dividindo tal posto com o posterior advento da TV. Considerando as particularidades do cinema, a presente pesquisa optou pela discussão de um ramo particular nesse complexo debate: o cinema de animação. Os filmes inscritos em tal modalidade limitavam-se, em princípio, ao público infantil, atendendo, apenas mais tarde, os nichos juvenis e adultos. De acordo com Denis (2010), a animação constitui uma

\footnotetext{
${ }^{1}$ http://tvfacopp.unoeste.br/tvfacopp/online/noticias.php?id=773\&pg=52 Acesso em 20 de janeiro de 2016.
} 
técnica empregada não apenas em desenhos, mas também em filmes de ação, terror, comédia e ficção científica. É o que se observa, por exemplo, em títulos revestidos de expressivos efeitos especiais, como E.T. O Extraterrestre (1982), O Senhor dos Anéis (2001, 2002 e 2003) e Avatar (2009) - sucessos de bilheteria em que mutantes, duendes e alienígenas eram criados em computador, animados por uma série de profissionais e, mais tarde, acoplados às cenas.

Moreno (1978), com base na Association Internacionale du Film d'Animation (1961), define o cinema de animação como toda criação cinematográfica realizada imagem por imagem. No cinema animado, "a concepção de filme é criada numa dimensão de irrealidade e descontinuidade não perceptível aos olhos antes de sua projeção em tela" (p.08). Dada a impossibilidade de abordar o cinema de animação em sua amplitude - tendo em vista a heterogeneidade de filmes que comportaria - fixar-nos-emos exclusivamente em uma seção dentro desse sinuoso e envolvente território: o desenho animado. Para Moreno, caracterizar-se-ia este pela construção de bonecos ágeis e estudo sistemático de seus movimentos (caminhar, correr, chorar, saltar, dançar etc).

Problematizar os aspectos estéticos de uma época exige do pesquisador certo rigor metodológico. As orientações da crítica especializada - Zilberman (1982), Stam (2003), Xavier (2008), Gabler (2009), Fossatti (2009) e Denis (2010), entre outros - tornam-se imprescindíveis no que tange ao aparato teórico. Contudo, o cuidado na forma de abordar as animações se faz fundamental, até para não incorrermos em certos reducionismos. Não pretendemos, com este artigo, esgotar as possibilidades de análise do cinema gráfico, mas apresentar indicadores e tendências que possam auxiliar eventuais leituras.

\section{CONCLUSÃO}

A trajetória da investigação científica permitiu a visualização de um complexo labirinto discursivo em que ganhava força, a partir dos princípios da dialogia, a interação entre o desenho animado e outros sistemas semióticos, como a literatura, os quadrinhos, a música, o folclore, a mitologia e o cinema "convencional". Nesse profícuo lastro cultural, evidenciava-se uma infinidade de propostas estéticas, transitando da geometrização das formas, com o astuto Gato Félix, ao figurativismo suntuoso e imponente da Disney; das formas ágeis e alongadas da Warner ao traço simples, limpo, intercalando poucos movimentos, da dupla Hanna-Barbera; da pop art e do psicodelismo de $\mathbf{O}$ submarino amarelo (1968) ao tom soturno de Tim Burton; da adaptação dos contos de fadas à releitura livre e envolvente de $\mathbf{O}$ Pequeno Príncipe (2015); do patriotismo exacerbado de Superman (1940) à contracultura de Asterix, o gaulês (1967) e Kiriku (1998); da construção caricata e simetricamente majestosa da computação gráfica ao delineamento de figuras com cores vivas e representação visual pouco realista, como sugerem Os Simpsons (1990) e Bob Esponja (2000) respectivamente. Constituíam um complexo corpus com mais de duzentas obras que, valendo-se da intertextualidade, operavam com a paródia, a alusão, o reboot e o crossover.

\section{REFERÊNCIAS}

ARIĖS, P. História Social da Criança e da Família. Rio de Janeiro: FCT, 1981.

AUMONT, J. \& MARIE, M. Dicionário Teórico e Crítico de Cinema. Campinas: Papirus, 2003.

DENIS, S. O Cinema de Animação. Lisboa: Edições Texto e Gráfica, 2010.

FOSSATTI, C. Cinema de Animação: uma trajetória marcada por inovações. Encontro Nacional de História da Mídia: mídias alternativas e alternativas midiáticas. Fortaleza, 2009. 
GABLER, N. Walt Disney: o triunfo da imaginação americana. Osasco: Novo Século, 2009.

MORENO, A. A Experiência Brasileira no Cinema de Animação. São Paulo: Arte Nova, 1978.

STAM, R. Introdução à Teoria do Cinema. Campinas: Papirus, 2003.

XAVIER, I. O Discurso cinematográfico: a transparência e a opacidade. São Paulo: Paz e Terra, 2008.

ZILBERMAN, R. A Literatura Infantil na Escola. São Paulo: Global Editora, 1982. 